\title{
PROCEEDINGS OF THE TWENTY-FIFTH ANNUAL MEETING OF THE AMERICAN SOCIETY FOR CLINICAL IN- VESTIGATION HELD IN WASHINGTON, D. C., MAY 8, 1933
}

Treatment of Pellagra with Liver Extracts. By David T. Smith and (by invitation) Julian M. Ruffin, Durham, N. C.

During the past two years a series of pellagra patients have been studied at the Duke Hospital. A basic diet was planned which contained all the normal necessary vitamins and minerals except vitamin B2 or $\mathrm{G}$. The patients maintained on this diet failed to make satisfactory improvement until vitamin $G$ in the form of liver extract was added to the diet. It has been demonstrated that the symmetrical skin lesions in pellagra are due to symmetrical exposure to sunlight and have no relation to nerve lesions in the spinal cord. Unilateral skin lesions could be produced at will by proper exposure to sunlight. Experimental black tongue in dogs has been produced with the same diet used as a basic diet for the clinical studies. This experimental black tongue can be cured by liver extracts.

The Urinary Excretion of Iodine. By GEORGE M. CuRTIS and (by invitation) Francis J. Phillips, Columbus, Ohio.

The urinary excretion of iodine by hospital patients without thyroid disease in this region is from 25 to 75 microgrammes daily. No iodized salt is used in the hospital diet. It is within normal range in patients with non-toxic nodular goiter and also in those with non-toxic diffuse colloid goiter. In patients with diffuse hyperplastic goiter with exophthalmos and with severe hyperthyroidism, it is greatly increased during the early exacerbation of severe, untreated toxicity. The urinary excretion of iodine increases greatly immediately following thyroidectomy. This increase is temporary. When iodine is quantitatively administered to patients with diffuse hyperplastic goiter with hyperthyroidism, the urinary excretion is at first low. There ensues a rising iodine excretion curve as clinical improvement follows. The urinary excretion of iodine is increased during early menstruation. This is correlated with the associated rise in the blood iodine.

Congenital Heart Block: Review with Report of Detailed Histo-Pathologic Study of the Second Case of Complete Congenital Heart Block Studied by Serial Sections Through the Conduction System. By Wallace M. YATER and (by invitation) JAMES A. Lyon and PAUL E. McNabB, Washington, D. C.

Cases of congenital heart block are not common. About forty cases have been reported in the literature which fulfill certain arbitrary criteria for the making of this diagnosis. The cause has usually been considered to be patent interventricular septum with anatomical break in the atrioventricular bundle. However, necropsy findings of only four cases have been reported and of these only two were studied by serial sections through the conduction system. One was a case of 2 to 1 heart block in which there was almost complete absence of the interventricular septum; the other was a case studied by Yater of complete 
heart block in which there were very unusual anomalies but in which a septal defect did not play a rôle. The case now reported is one of an infant who had a defect in the interventricular septum in its middle upper portion. There was found a complete interruption of the bundle of His by the defect. In fact, practically the whole bundle was missing. The electrocardiogram, however, showed the QRS complex to be of the supraventricular type. The diagnosis of complete heart block due to patent interventricular septum was made during life.

Significance of Inorganic Sulphate Coefficient or Clearance in Renal Disease. By John W. Macy (by invitation) and Norman M. KeIth, Rochester, Minn.

Inorganic sulphate concentration was determined in blood serum and urine during a given period of urine excretion. The coefficient or clearance was determined by the following formula:

\section{$\frac{\text { Per cent sulphate concentration in urine }}{\text { Per cent sulphate concentration in blood serum }} \times$ minute volume of urine.}

In twelve normal individuals the sulphate coefficient or clearance was very constant from hour to hour, the variation being less than in the corresponding urea and creatinine coefficients. This fact suggests that the inorganic sulphate coefficient might be useful as a standard with which the coefficient of other substances might be satisfactorily compared.

In renal disease the sulphate coefficient is in general lowered in proportion to the degree of insufficiency. In some cases of this series, the sulphate coefficient appears to be decreased when other functional tests, including urea clearance, are within normal range. This suggests that the sulphate coefficient or clearance may have an important place in those cases in which early renal insufficiency is suspected.

The Effect of Gelatin Diets in Nephritis. By G. P. Grabfield, Boston, Mass.

Previous studies of nephritis have indicated that there is some alteration in patients with Bright's disease in their handling of sulphur, more especially in relation to the nitrogen. Therefore, in the present study it was decided to try the effect of sulphur-poor diets on patients with Bright's disease. The problem of providing adequate amounts of nitrogen without sulphur was solved by using gelatin as the source of practically all the dietary nitrogen. In practice, standard nephritic diets were used; patients were studied for three-day periods and during the test period, practically all the protein of the diet was given to the patient in the form of gelatin in the same amount as the previous protein of the diet. These diets were difficult to take and the only cases reported are those which succeeded in eating all the diet.

Unfortunately, few control experiments of this type are recorded in the literature but those that are, indicate that gelatin is an incomplete protein and is only partly utilized. The degree of utilization varies and the estimates are that from 11 to 40 per cent must be made up by the breakdown of body protein. The interesting thing about the figures as shown, is that if we take the sulphur as an index of the amount of nitrogen metabolized, it remains essentially the same during the gelatin periods as previously. As these diets were adequate except for the protein and sulphur, it seems to us that this may be taken as an indication that there is an alteration in the utilization of sulphur in these patients with Bright's disease. In other words, these figures indicate that the 
amount of the sulphur-rich moiety of the protein molecule that is metabolized in such patients is only partly dependent upon the diet.

The Effects of Posture (Standing) on the Serum Protein Concentration and Colloid Osmotic Pressure of Blood from the Foot in Relation to the Formation of Edema. By JoHN B. Youmans and (by invitation) H. S. Wells, Dorothy Donley, and D. G. Miller, Nashville, Tenn.

The influence of posture on the serum proteins and osmotic pressure of blood in the foot was studied with reference to formation of edema, particularly in persons with slightly lowered serum proteins. Others have shown a general concentration of blood in the erect posture, apparently due to loss of fluid from the vessels in the dependent tissues, but protein concentration and osmotic pressure of blood from the foot have not been determined. Normal subjects after standing approximately an hour showed a 17 to 40 per cent concentration of proteins and a 24 to 64 per cent increase in osmotic pressure in blood from the foot. In all cases the rise in osmotic pressure was relatively greater than the concentration of protein. Concentration was much greater in the foot than in the arm. The escape of fluid was indirectly indicated by an increase in leg volume but pitting edema was absent in most normals. Patients with edema showed an increase in proteins of 14 to 33 per cent and in osmotic pressure of 23 to 46 per cent but the average increases were less than in normals, while the increase in leg volume was greater and the edema was demonstrably increased.

A Study of the Nasal Secretions in Disease of the Upper Respiratory Tract.

By Perrin H. Long and (by invitation) Eleanor A. Bliss and Harriet

M. Carpenter, Baltimore, Md.

Studies of the nasal secretions during "colds" have shown that in the early hours of a "cold," many epithelial and mononuclear cells are found. By the third day the cellular content of the nasal secretions is chiefly made up of polymorphonuclear leukocytes. In many instances stained slide preparations of the nasal secretions late in "colds" failed to show appreciable numbers of bacteria. It is suggested that the cellular reaction of the nasal secretions in "colds" is a response to the infecting filterable agent rather than to the bacterial flora of the nasal passages.

Contraction of the Spleen in a Case of Anemia with Splenomegaly. By D. K. Miller (introduced by C. P. Rhoads), New York City, N. Y.

Contraction of the spleen was studied during the intravenous injection of liver extract in a patient with anemia and splenomegaly. This afforded an opportunity to ascertain certain facts regarding the function of the human spleen as a reservoir of red and white corpuscles and blood platelets.

The spleen was visualized by $\mathbf{x}$-ray. Its area was measured before and after the injection of liver extract. The contraction occurred during the injection, which was given over a period of twenty minutes. The spleen regained its original size after one-half to six hours.

In a typical study the surface area of the spleen, as measured from the $\mathrm{x}$-rays with a Keuffel and Esser planimeter, was $90.3 \mathrm{sq} . \mathrm{cm}$. before the injection. Immediately after the injection the surface area was $32.3 \mathrm{sq} . \mathrm{cm}$. Twenty-four hours later the area was 89.1 sq. cm. Accompanying this contraction there was an increase in the red cell count of 15.1 per cent. The hemoglobin increased 21.5 per cent, and the white cell count 54.0 per cent. An 
increase in the number of blood platelets of 120 per cent occurred. The fragility of the red cells to sodium chloride solution was not altered.

Blood volume determinations by the vital red method of Rowntree showed no appreciable alteration. There was a decrease in the plasma percentage of 7.7 per cent.

From data of this nature it has been possible to estimate the relative cellular composition of the blood given off from the splenic reservoir into the general circulation as a result of induced and observed contractions of the spleen.

The Nature of the Muscular Weakness in Graves' Disease. By E. SHORR,

H. B. Richardson and H. G. WolfF, New York City, N. Y.

Muscular weakness is a common symptom in Graves' disease. In such patients a very constant abnormality is the presence of excessive amounts of creatin in the urine. Creatin in muscle has been shown to be combined with phosphoric acid as a labile compound, phosphocreatin (Fiske and Subbarow), now considered to be of primary significance for muscular contraction. From experiments on certain pathological states, it appears probable that glycin is an important precursor of creatin. This amino-acid is readily synthesized in the body, chiefly in the liver.

Recently, considerable information has been obtained concerning the relation between the muscular weakness and the disturbance of creatin metabolism in progressive muscular dystrophy. Since the muscular weakness in Graves' disease is often very great, and a creatinuria is common to both conditions, the creatin metabolism of patients with Graves' disease was investigated. Several analogies between the two syndromes were revealed. Thus, in both (1) the ability to retain ingested creatin (presumably as phosphocreatin) was markedly diminished; (2) the ingestion of glycin resulted in large increases in creatin elimination, frequently greater in Graves' disease than in advanced cases of progressive muscular dystrophy. In some instances the rise was transitory, falling to lower levels or disappearing with continued glycin feeding; (3) the ability to form glycin, as measured by hippuric acid excretion after the administration of sodium benzoate, was unimpaired. Furthermore, following ingestion of sodium benzoate, there was frequently observed a sharp increase in the creatin output, the significance of which is yet unknown.

An additional point of resemblance was furnished by the observation that long-standing cases of Graves' disease showed anatomical changes in the skeletal muscle similar in many respects to those found in progressive muscular dystrophy (Askanazy).

Following the administration of iodine to patients with Graves' disease, as was previously observed (Palmer et al.), there was a progressive fall in creatinuria to the normal level, usually accompanied by a fall in the basal metabolism. During the latter phase, we gave creatin and glycin again, but now no increase in creatin output resulted. This is analogous to what occurs in progressive muscular dystrophy after prolonged feeding of glycin. Additional ingestion of glycin and creatin then produces no increase in creatin output (Thomas, Milhorat and Techner).

The factors causing these disturbances of creatin metabolism in Graves' disease are still obscure. It is postulated that the processes maintaining the integrity of the phosphocreatin mechanism are taxed too severely by the persistently high metabolism. One of these, the endogenous formation of glycin, was found to be normal. However, though adequate in proportion to the body weight and the normal basal metabolism, its production may be low in proportion 
to the needs of an elevated total metabolism. The increased demands resulting from the latter may lead to a progressive depletion of the elements involved in the phosphocreatin system. Whether iodine acts directly on this muscle mechanism, in addition to reducing the basal metabolism, cannot be stated.

Conclusion. The muscular weakness in Graves' disease is the result of a reparable impairment of the phosphocreatin mechanism, and is of the nature of an acute muscular dystrophy, similar in many respects to the disturbance in progressive muscular dystrophy.

The Effect of Convulsant Drugs on the Cerebral Vessels. By Stanley CobB and (by invitation) JACOB E. Finesinger, Boston, Mass.

This paper is a report of microscopical observations through a window in the skull of the small arteries of the pia, and of their reactions after the administration of convulsant drugs to the animal under observation. The drugs used were caffeine, wormwood oil, homocamfin, camphor monobromate and picrotoxin. The intravenous introduction of large doses of caffeine produced an acute constriction of the pial arteries followed by a generalized convulsion. Small doses of wormwood oil gave a slight constriction of the pial artery followed by a generalized convulsion; large doses of wormwood oil produced a dilatation of the pial arteries before the onset of the generalized convulsion. Homocamfin and picrotoxin produced a slight constriction of the pial artery preceding the convulsion. Camphor monobromate gave a dilatation of the pial arteries preceding the convulsion. These experimental convulsions were not preceded by a consistent type of vascular response to the drugs used.

The Nonprotein Iron of the Blood. By J. F. McIntosh, Peiping, China.

Relatively little attention has been paid to that part of the iron of the blood which is not contained in the hemoglobin molecule. Most investigators have considered it as negligible. Scarcely any determinations of it have been made in clinical cases.

The nonprotein iron of whole blood has been determined directly by analysis of the trichloracetic acid filtrate. In normals, the average value found was $1.02 \mathrm{mgm}$. per $100 \mathrm{cc}$. A variety of anemic cases were studied, including pernicious anemia, achlorhydric hypochromic anemia, and secondary anemias due to hemorrhage, cancer, and various infections. In these, the nonprotein iron was reduced in proportion to the degree of anemia. The different diseases do not show any grouping which deserves emphasis.

The greater part of the nonprotein iron is to be found in the red cells.

The Case of Captain Charles Martell: What It Has Taught Us About Generalized Osteitis Fibrosa Cystica. By WALTER BAUER and (by invitation) Charles L. Short, Boston, Mass.

The diagnosis of generalized osteitis fibrosa cystica was first made in this country by DuBois in 1926 . Through the kindness and generosity of Dr. DuBois, we have been privileged to study this patient, Captain Charles Martell, at various times during the ensuing six years. Because of his courage, interest in clinical investigation and desire to live, as well as to help others live, he permitted detailed clinical and metabolic studies on numerous occasions, submitted to eight operations and asked that a complete necropsy be done at the time of his death. 
A detailed review of these studies reveals not only the clinical and metabolic course of generalized osteitis fibrosa cystica, its complications, the metabolic changes resulting from these complications, but also demonstrates the difficulty that may be encountered in finding the offending parathyroid tumor in this disease, as well as the pathological changes resulting from hyperparathyroidism of fifteen years duration.

The Conversion of Glycerol to Glucose by the Animal Organism. By F. H. LASh met (by invitation) and L. H. Newburgh, Ann Arbor, Mich.

In its metabolism, 10 per cent of fat is converted to glycerol. On the basis that 100 per cent of glycerol is converted to glucose, it has been customary to consider 10 per cent of the fat of the diabetic diet as available glucose.

The data, upon which the conclusion is based that glycerol is completely converted to glucose, are very unconvincing, even as originally presented, and especially so when recalculated.

Our investigation, employing more recent methods than were available to older observers, seems to show that less than 30 per cent of glycerol is converted to glucose. If our work is substantiated, it is evident that only 2 or 3 per cent of fat is converted to glucose.

Studies on the Origin of Plasma Proteins. By Hobart A. Reimann and (by invitation) Grace Medes and Luther C. Fisher, Minneapolis, Minn.

Previous experiments indicated that an increase of blood viscosity due to increase of globulin and fibrinogen caused enhancement of the agglutination of bacteria. Studies were then made to locate the source of these proteins which appear to be associated with the immune defense mechanism. There are four theoretical sources of fibrinogen: $(a)$ liver, $(b)$ erythrocytes, $(c)$ bone marrow, $(d)$ leukocytes. Considerable presumptive evidence favors the latter two, especially the leukocytes.

Leukocytes were obtained by injecting aleuronat or gum acacia into the pleural cavities of rabbits. The cells were disintegrated by freezing with liquid air and triturating in a mortar. The resulting viscid mass was redissolved in salt solution, dialyzed and fractionated with sodium sulfate. Proteins with the salting-out characteristics of fibrinogen, globulin and albumin were present. Immunologic tests are under way to test the identity of these proteins with their counterparts in the plasma.

Heavy suspensions of leukocytes in broth were placed in cellophan capsules and embedded subcutaneously in rabbits. After 4 to 7 days the capsules were removed. The leukocytes had largely disintegrated and globulin- and fibrinogen-like proteins were detected in the broth. Leukocytes were then destroyed in vivo by benzol injections or by exposure to $\mathrm{x}$-rays. In one benzol experiment the globulins and fibrinogen increased markedly as the number of circulating leukocytes fell. During the period of aplasia of the marrow, the fibrinogen diminished. Other experiments failed to give striking results. In general, the fibrinogen tended to increase, and the total protein to diminish at the expense of the albumin fraction. The marked leukopenia produced by $\mathrm{x}$-rays caused but little change in the blood proteins. The fibrinogen increased somewhat immediately following the diminution of leukocytes.

These experiments indicate that globulin and fibrinogen may in part be derived from the decomposition of the leukocytic cells, especially of the polymorphonuclear type in the circulation or in the hematopoietic system. 
Allergy and Immunity in Tuberculosis. By JoNAS S. FRIEDENWALd and (by invitation) Herbert Rothschild and Clarence Bernstein, Baltimore, Md.

A group of guinea pigs was made immune to tuberculosis and allergic to tuberculin by inoculation with a virulent strain of tubercle bacilli. When allergy had been well established, one-half of the animals were desensitized by daily subcutaneous injections of Koch's O.T. in increasing doses. When allergy had been completely suppressed, the desensitized animals together with the allergic animals and a group of normal controls were inoculated in the groin, in the eye, and in the skin with a virulent strain of tubercle bacilli. The injections of tuberculin in desensitized doses were continued daily. The results showed that the loss of allergy by desensitization was not accompanied by any loss of immunity.

\section{Heterologous Scarlet Fever. By James D. Trask and Francis G. Blake,} New Haven, Conn.

Two cases of scarlet fever which failed to respond to large doses of therapeutic scarlet fever antitoxin were found to have a heterologous toxin in their blood. The blood serum from these patients collected during the active stage of the disease elicited strongly positive skin reactions in certain Dick negative test subjects and no reaction in Dick positive subjects. In vitro, the serum was neutralized by the blood serum of the Dick positive individuals but not by that of the Dick negative individuals.

A toxin was prepared from the hemolytic streptococci isolated from the two patients. Both in the reactions it elicited on intracutaneous injection and by the results of neutralization tests it corresponded with the toxin in the blood samples mentioned above.

Accordingly, the above results taken in conjunction with our previous studies show that heterogenicity exists among the toxins found in the blood during scarlet fever and among the antitoxins found in the blood serum of normal individuals.

Electrocardiograms that Record the Potential Variations Produced by the Heart Beat at a Single Point. By PAUL S. BARKer, Frank N. Wilson and (by invitation) Franklin D. Johnston, Ann Arbor, Mich.

A method has been devised which makes it possible to record the potential variations produced by the heart beat at a single point. This method has been used to explore the electric field produced by the heart at the body surface in bundle-branch-block, ventricular hypertrophy, coronary occlusion and other cardiac conditions. By this means, it is possible to compare the potential variations that occur at points near the heart with the potential variations of the extremities. In general, it is found that the potential variations of a given extremity are similar to those that occur on those surfaces of the heart that face toward the attachment of that extremity. In the common type of bundlebranch-block and in left ventricular enlargement the potential variations of the left arm are similar to those that occur over those portions of the precordium that overlie the left ventricle; the potentials of the left leg are similar to those that occur over those portions of the precordium that overlie the right ventricle. Characteristic curves are obtained from the precordium when the anterior surface of the heart is infarcted. 
The Effect of Vagus and Sympathetic Stimulation on the Coronary Flow in Revived Human Hearts. By William B. Kountz (introduced by David P. Barr), St. Louis, Mo.

Human hearts have been revived in the body by perfusion. The hearts were perfused through an aortic cannula until they began to beat strongly. Cannulae were then inserted into the right coronary artery and into the circumflex branch of the left coronary artery. These were then connected to a reservoir of perfusion fluid, the height of which could be regulated so as to obtain any desired pressure. In some experiments another reservoir containing Locke's solution free of calcium or with excess of calcium was arranged in the perfusion circuit. The flow of fluid from the reservoirs was measured by a volumetric recorder.

When the coronary vessels were perfused with buffered Locke's solution containing at least 15 per cent blood, stimulation of the peripheral end of the vagus nerve slowed the heart rate and increased the coronary flow. Stimulation of the sympathetic produced exactly opposite effects under the same circumstances.

Further analysis was made by stopping the heart through removal of calcium from the perfusing solution or through the addition of an excess of calcium. In some experiments changes in the $\mathrm{pH}$ of the perfusion fluid in the range from 7.0 to $7.8^{\circ}$ were made.

It was found that when hearts were stopped by removal of calcium or by reducing the $\mathrm{pH}$ of the perfusion fluid to about 7.0 vagus stimulation had no influence on the coronary flow. Sympathetic stimulation on the other hand increased the flow. When the hearts were stopped by an excess of calcium or by increasing the $\mathrm{pH}$ to about 7.8 vagus stimulation increased the coronary flow, while sympathetic stimulation had no influence upon it.

In the beating heart the mechanical factor of change in heart rate makes it difficult to evaluate the effect of the sympathetic and vagus activity on the heart. It is suggested that changes in the coronary flow in the arrested hearts may be due to change in tone.

Further Observations. on the Use of Chest Leads in the Electrocardiographic Study of Coronary Occlusion. By Charles C. Wolferth and (by invitation) Samuel Bellet, Thomas M. McMillan, and Francis Clark Wood, Philadelphia, $\mathrm{Pa}$.

Fifty-seven cases of acute coronary occlusion and 280 controls, both normal and pathological, were studied with chest leads and limb leads. The following facts developed:

1. Twenty-three of our fifty-seven cases of acute coronary occlusion showed signs of recent cardiac infarction in an anteroposterior chest lead (Lead IV) and not in limb leads, at some time during their course.

2. Three types of left ventricular infarction have been seen at necropsy: the anterior ( 5 cases), the posterior (1 case) and the lateral (1 case). Lead IV helps to differentiate these types electrocardiographically. In our series of 57, 33 were anterior, 18 were posterior, 5 were probably lateral, and 1 was not classified.

3. Huge upright T-waves in Lead IV probably signify acute or subacute anterior infarction.

4. The advantage of Lead IV over limb leads is seen mainly in the study of cases of anterior infarction. Twenty-one of thirty-three acute anterior cases, at some time during their course, showed diagnostic findings in Lead IV and not 
in limb leads. Moreover, Lead IV sometimes helps to differentiate T-1 inversions produced by healed anterior infarction from those due to other causes.

5. In our cases the pain of anterior infarction has usually been situated lower in the chest than the pain of posterior infarction.

6. Anterior infarction seems to have a less favorable prognosis for life and for adequate recovery than posterior infarction.

7. A standard normal electrocardiogram in the anteroposterior chest lead is as readily obtainable as a standard in limb leads.

8. S-T interval deviations caused by conditions other than acute coronary occlusion are, if anything, less confusing when chest leads are used with limb leads. 'They rarely resemble the typical electrocardiographic picture of either of the two common types of coronary occlusion.

\section{Bone Lesions in Yazes. By Thomas B. Turner and (by invitation) George M. SAUnders, Baltimore, Md.}

Approximately 10 per cent of 1100 yaws patients studied in Jamaica exhibited lesions of the bones, although among individuals infected less than five years the incidence was 14 per cent. The characteristic lesion as revealed by roentgen ray consists of multiple small areas of rarefaction in the cortex with or without periosteal proliferation; rarely, periostitis occurs alone. Often there is new bone formation about the areas of rarefaction giving rise to clinically recognizable enlargement and deformity of the bone. The long bones are chiefly affected. The onset of typical lesions has been observed as early as one month and as late as fifteen years after infection with yaws. Persistent dull pain is the most prominent symptom and active lesions may persist for several years, eventually healing spontaneously or extending to involve the overlying soft parts with subsequent development of chronic ulcers. If not too far advanced there is prompt response to anti-yaws treatment. Photographs of the clinical and roentgenological appearance of typical bone lesions were shown.

\section{Preliminary Report on the Treatment of Chronic and Subacute Infectious} Arthritis by Artificial Fever. By LawRENCE A. КоHN and (by invitation) StafFord L. W ARREN, Rochester, N. Y.

Forty-three patients, in the main with purely atrophic, proliferative, and some mixed types (infectious and degenerative arthritis), in various stages of disability, deformity, and chronicity (six months to fourteen years) have been subjected to one or two treatments of artificial fever. No cases of gonorrheal origin or purely degenerative arthritis have been included. Twenty-one patients were treated in 1931; of these five have not returned in 1933 (one was not improved and the rest were improved when last heard from, after 1 to 14 months). Twenty-two patients were treated in 1932 (of these, two have not returned and one was unimproved one month later and has been lost sight of). The results have been quite consistent in thirty-five patients, in all but two of whom pain has rapidly diminished and mobility of joints has increased; a steady improvement in the condition of the patient, a gain in weight (2 to $17 \mathrm{kgm}$.), and disappearance of pallor have occurred in the following four to six months.

Relapses have occurred at the end of 12,20 , and 24 months respectively in three patients, in whom another treatment has been successful in giving relief. Eight incapacitated patients have been able to earn a living. 
Antibody Response to Pneumococcic Infections. By Maxwell Finland and Alexander W. Winkler (introduced by Chester S. Keefer), Boston, Mass.

One hundred and fifty-eight patients from whom pneumococci of various types (Cooper) other than Type I were isolated were studied with reference to the formation of antibodies. Of these, 110 were patients with pneumonia and the remainder had other acute or chronic respiratory infections. Tests for serum agglutinins were carried out before and after crisis by the use of antigens prepared from a variety of type-specific pneumococci. Each serum was tested with one or more antigens of the type homologous with that recovered from the patient and, in addition, against a number of antigens of heterologous types. In the case of Types II, III, V and VIII protection tests were also carried out.

The results showed that agglutinin formation can be demonstrated in the course of pneumonia and occasionally of other infections associated with the finding of some of the new types of pneumococci. The specificity of the antibody response is similar to that commonly observed in infections with Type I pneumococci. In particular, homologous type-specific antibodies were demonstrated in patients from whom the following types were obtained: Types II, III, V, VII, VIII, IX, XII, XIV, XVII, XVIII and XIX. Among the patients with Types II and V (IIa, Avery) pneumococci, homologous typespecific antibodies were found for each type, with only occasional development of heterologous antibodies as demonstrated by mouse protection tests. With Types III and VIII (atypical III, Sugg and Harris) a similar specificity in the production of antibodies occurred; but, in addition, there was some production of Type III antibodies in pneumonias associated with Type VIII pneumococci and vice versa.

The findings, in general, tend to confirm the biological identity of the newly classified types and point toward their etiological relationship to human disease.

Digestion Efficiency in Simple Undernutrition. By J. M. STrang and H. B. McClugage (by invitation) and Frank A. Evans, Pittsburgh, Pa.

Nine undernourished patients increased their diets to a daily average of 3475 calories on which they gained an average of $7.3 \mathrm{kgm}$. in 5.6 weeks. The average weight of the food was 1926 grams per day. The average daily weight of the stool was 165 grams or 8.5 per cent of the food intake. This ratio varied according to the water content of food and stool. The food solids bore a fairly constant relation to the stool solids from week to week. The average weight of the food solids was 549 grams, of the stool solids, 31 grams. This represents a digestion and absorption efficiency of 94 per cent. The nitrogen in the stools averaged 1.3 gram per day, or 12 per cent of the food nitrogen.

These studies indicate an ability on the part of patients with uncomplicated undernutrition to digest and absorb sufficient food to gain rapidly.

Congenital Heart Disease Complicating Pregnancy: A Report of Sixteen Cases. By Burton E. Hamilton (by invitation) and Robert Sterling Palmer, Boston, Mass.

Congenital heart disease is not a common complication of pregnancy. At the Boston Lying-in Hospital in over 500 cases of organic heart disease, congenital heart disease comprises less than three per cent. It is found as a complication of pregnancy once in 3000 patients. This very rarity, plus the fact that the striking physical signs of congenital heart disease sometimes impress 
the first observer unduly and lead him to make an unnecessarily grave prognosis and finally a practical clinical lesson which we have drawn from our experience, has prompted us to make this report. We are presenting in addition to our sixteen cases the scattered reports of fifteen cases encountered in the literature.

We feel justified in drawing the following conclusions:

1. Coarctation of the aorta is to be considered in any case of unexplained persistent hypertension. The prognosis for the mother when this condition complicates pregnancy is probably good. The fetus may die in utero, possibly due to diminished circulation to the lower half of the body.

2. Congenital complete heart block is not a serious complication of pregnancy.

3. Patent ductus arteriosus is compatible with successful childbearing, only one in eleven cases having symptoms which could be considered at all serious. We suspect that the same may be said of intraventricular septal defect if operative delivery and obstetrical manipulations in themselves likely to induce shock can be anticipated and avoided. The danger probably lies in a reversal of the left-right to a right-left shunt brought about by a fall in systemic pressure.

4. Experience with six pregnancies in one patient with preexisting rightleft shunt suggests that operative delivery or obstetrical procedures likely to induce hemorrhage or shock may cause a serious and alarming exacerbation of this shunt. However, compensatory mechanisms already present may make the danger less formidable in these cases.

Do the Thebesian Vessels Play Any Role in Supplying Blood to the Heart? By L. N. Katz and (by invitation) KenNeth Jochim and ANNe BoHnING, Chicago, Ill.

Wearn's contention of the auxiliary rôle of the Thebesian vessels has recently been questioned. We have reinvestigated the problem, using a system by which the cannulated coronary arteries and coronary sinus form a circuit distinct from the cardiac chambers and great vessels; the only communication possible between the two circuits is by way of the Thebesian vessels. Bismuth injected into the cardiac circuit appeared in the coronary circuit as evidenced by chemical analysis of the coronary sinus blood. Bacteria injected into the coronary circuit also appeared in the coronary sinus blood and were found histologically in the capillaries and coronary vessels. The Thebesian vessels can therefore carry blood from the heart chambers into the coronary circuit but the amount carried is still undetermined.

The Calorigenic Action of Thyroglobulin and its Constituents. By J. Lerman and W. T. Salter, Boston, Mass.

It has previously been shown by us that thyroxin polypeptide is as active when given by mouth as when given parenterally, and that its activity is proportional to its iodine content when compared with crystalline thyroxin. Using the metabolic response of untreated myxedema patients to thyroxin polypeptide given in dosage of one milligram by mouth daily as a standard, we find, in three assays of whole thyroid gland with an equivalent thyroxin content, and in four assays of whole thyroid gland with an equivalent total organic iodine content, that the calorigenic action of whole thyroid gland depends upon its total organic and not upon its thyroxin (active) iodine content.

In another study, 20 patients with treated myxedema were given, in succession, thyroid gland preparations from different sources for periods of time sufficient to determine the maintenance level of metabolism for each preparation. 
The results indicate that the ration of a preparation of thyroid which will maintain a definite level of metabolism in a given patient or change this level is dependent upon its total organic iodine and not its thyroxin (active) iodine content. Since diiodotyrosin (the soluble iodine fraction in iodothyroglobulin) is inactive calorigenically when given alone, there remains to be explained the mechanism by which it assumes calorigenic properties when linked with other amino-acids in iodothyroglobulin.

One patient with myxedema was fed thyroglobulin obtained from hyperplastic glands; two others were fed thyroglobulin obtained from colloid glands. The calorigenic response in each case was proportional to the total iodine content. Diiodotyrosin peptone, obtained by peptic digestion of thyroglobulin, was inactive in one patient, whereas thyroxin peptone obtained in this way was active in the same patient in proportion to its iodine content.

The results thus far indicate that no calorigenic activity is lost in the isolation of thyroglobulin from whole thyroid gland and that diiodotyrosin loses its activity in the first stage of proteolytic digestion of thyroglobulin.

The Elastic Properties of the Emphysematous Lung and Their Clinical Significance. By Ronald V. Christie, Montreal, Can.

The elastic properties of the lung have been analysed in cases of emphysema by means of simultaneous tracings of the tidal air and interpleural pressure. With inspiration and expiration the interpleural pressure is found to fluctuate around that of the atmosphere, and an almost complete loss of the pulmonary elasticity can be demonstrated. These changes can also be shown by vital capacity tracings, the reserve air if taken alone being greater than that taken after the complemental air. The respiratory level also shows characteristic fluctuation.

The significance of these findings with regard to the increase in lung volume, and the dyspnoea and orthopnoea in emphysema is discussed, the paradoxical movement of the diaphragm during expiration being emphasized and explained on what is shown to be an active expiratory effort of the extrinsic muscles of respiration. To prevent this paradoxical movement a tight abdominal binder has been used in the treatment of emphysema, with encouraging signs of symptomatic relief.

The relationship of the loss of elasticity to unequal ventilation of the lungs in emphysema is also discussed.

The Association of Acalcification of Dentine with Hypoparathyroidism in Rats and the Cure of Same with Parathormone, with some Correlated Observations in Man. By Fuller Albright and (by invitation) Moses S. STrock, Boston, Mass.

The first interrelationship to be demonstrated between the parathyroid glands and calcium metabolism was in 1911 by Erdheim. He showed that parathyroidectomy in the rat is followed by acalcification of that dentine which is formed subsequent to the operation. It has surprised some observers that acalcification should occur in hypoparathyroidism when decalcification is such an important part of hyperparathyroidism. The work of Erdheim has been repeated with similar results, and, with the aid of parathormone, strata of acalcified dentine followed by strata of calcified dentine have been produced at will. Decalcification of the dentine was never produced. The data are in accordance with the view that metabolic processes can cause acalcification of dentine, but not decalcification. Confirmatory observations from the teeth of patients with hypo- and hyperparathyroidism are made. 
Observations upon the Refractory Period of the Auricular Extrasystole in the Mammalian Heart. By E. Cowles ANdrus and (by invitation) PAUL PADGET, Baltimore, Md.

The Production of Inflammatory Lesions in the Hearts of Animals Allergic to Hemolytic Streptococcus. By Caroline C. Bedell and Rawlex M. Penick (by invitation) and Benjamin M. Baker, JR., Baltimore, Md.

Seegal, Seegal and Jost recently produced, by the intrapericardial injection of the homologous antigen, an intense inflammatory reaction in the pericardium, heart and aorta of rabbits sensitized to egg white. The present report has to do with similar observations upon animals made sensitive to a beta hemolytic streptococcus. Twenty-eight normal rabbits received, over a period of several weeks, $0.1 \mathrm{cc}$. of a saline suspension of living organisms into the skin. At varying intervals after the beginning of sensitization the pericardial sacs were exposed and $2 \mathrm{cc}$. of vaccine prepared from the streptococcus employed were injected. The animals were killed twenty-four hours to six days later and the hearts were examined both grossly and microscopically. Twenty-five of these showed varying degrees of pericardial and myocardial inflammatory reactions somewhat similar to the changes described by Seegal, Seegal and Jost. One other had extensive changes confined to the pericardium only and the other two had but slight pericardial changes. Experimental lesions were compared with the spontaneous lesions of thirty-one normal rabbits. Another control group was composed of twenty normal unsensitized rabbits which were subjected to the pericardial injections similar to those described above. Many of these had minimal pericardial inflammatory reactions but in all but one the heart muscles were normal.

The Action of Oxygen in Counteracting the Effects of Alcohol. By Alvan L. BARACH, New York City, N. Y.

The ingestion of alcohol by a subject performing a standard exercise test resulted in a marked increase in the pulse rate, respiratory rate and pulmonary ventilation above the response of the same subject without alcohol. When oxygen was inhaled instead of air, there was a consistent reduction in the pulse rate, respiratory rate and pulmonary ventilation of the alcoholic subject. The inhalation of oxygen in the normal exercising individual also resulted in a lower pulse rate, respiratory rate and pulmonary ventilation than that obtained when the exercise was conducted in air, but the percentage difference between the effect of oxygen in the alcoholic subject was considerably greater than in the non-alcoholic subject, suggesting that the inhalation of oxygen tended specifically to counteract the handicapping influence of alcohol on muscular exercise.

The psychological manifestations of alcoholism were slightly too moderately relieved or prevented by the inhalation of oxygen, but this varied considerably in individual subjects.

The Simple Dialysate Nature of Edema Fluids, Contrasted with the Specialized Composition of Cerebrospinal Fluid. By Dorothy Rourke Gilligan and Marie C. Volk (by invitation) and Herrman L. Blumgart, Boston, Mass.

The concentrations of certain electrolytes and non-electrolytes in ascitic, chest and subcutaneous edema fluid have been compared to the concentrations in both arterial and venous blood serum, in twenty-seven instances in patients with nephritis, cardiovascular disease, carcinoma, and cirrhosis of the liver.

The differences in the concentrations of the various electrolytes between the sera and fluids are governed by the differences in the protein contents, regard- 
less of the site of fluid formation or the underlying diseased state studied. The distribution, in terms of water content, of sodium, chloride, and bicarbonate between serum and the edema fluids is in close agreement with that expected for simple dialysates in accord with Donnan's membrane equilibrium law, when the source of the blood sample is considered. The average distribution ratios found were

$$
\begin{gathered}
\frac{\left(\mathrm{Na}^{+}\right) \text {edema fluids }}{\left(\mathrm{Na}^{+}\right) \text {serum }}=0.96 ; \frac{\left(\mathrm{Cl}^{-}\right) \text {serum }}{\left(\mathrm{Cl}^{-}\right) \text {edema fluids }}=0.98 \text {; and } \\
\frac{\left(\mathrm{HCO}_{\mathrm{s}}^{-}\right) \text {serum }}{\left(\mathrm{HCO}_{\mathrm{s}}^{-}\right) \text {edema fluids }}=0.96,
\end{gathered}
$$

for serum representative of blood midway between arterial and venous. The theoretic Donnan ratio for this series was 0.955 . These results indicate that no bicarbonate is "bound" in the serum. The distributions of calcium, potassium, and inorganic phosphate indicate that fractions of these substances are bound in the serum. The concentrations of the non-electrolytes, sugar, total nonprotein nitrogen and creatinin were practically equal in serum water and corresponding fluid water, in accord with a simple dialysate nature for these body fluids. The distribution of the substances between serum and the edema fluids corresponds to the distribution found by Greene et al. (J. Biol. Chem., 1931, xci, 183) and others, between plasma and " in vivo" dialysates.

Our investigations show that the edema fluids studied are simple dialysates in equilibrium with blood plasma. This finding supports the hypothesis that these fluids have collected in abnormal amounts by virtue of an imbalance of the normal forces of formation and reabsorption and is in harmony with the concept that edema is primarily a quantitative rather than a qualitative abnormality.

A comparison of our studies with the spinal fluid measurements of other investigators has an important bearing on the theories regarding the mechanism of spinal fluid formation by the choroid plexuses, for it indicates that spinal fluid is not a simple dialysate. The concentrations, expressed in terms of water content, of sugar, creatinin, total nonprotein nitrogen, and inorganic phosphate, are much lower in the spinal fluid than in the serum, contrasted with practically equal concentration of these constituents in edema fluids and serum. The calcium content of spinal fluid is lower than the calcium content of edema fluid with similarly low protein content or than the "in vivo" dialysate. The difference in chloride concentration between serum and spinal fluid is much greater than the chloride difference between serum and the edema fluids or the "in vivo" dialysate, when the differences in protein concentrations between the sera and the two types of fluid are similar. Expressed in terms of water content, the ratio $\left(\left(\mathrm{Cl}^{-}\right)\right.$serum $/\left(\mathrm{Cl}^{-}\right)$spinal fluid) is too low to accord with the theoretic Donnan ratio and conversely, the ratio $\left(\left(\mathrm{HCO}_{3}^{-}\right)\right.$serum/ $\left(\mathrm{HCO}_{3}^{-}\right)$spinal fluid) is too high. The choroid plexus must be considered a specialized structure and the fluid elaborated from it a specialized fluid rather than a simple dialysate.

The Basal Respiratory Quotient and the Effect of a High Fat Meal on the Respiratory Quotient and Heat Production of Normal and Obese Individuals. By BYron D. Bowen and (by invitation) Fred R. GRIFfith, Jr., and Grace E. Sly, Buffalo, N. Y.

An attempt to demonstrate a qualitative metabolic difference between obese and normal individuals was undertaken. All subjects had previously taken an 
unrestricted diet and were given the same test meal (100 grams of butter and 50 grams of mayonnaise). The Tissot spirometer and the Haldane gas analyzer were used. Tests not showing fairly steady ventilation volumes and $\mathrm{CO}_{2}$ percentages in the expired air were rejected, in order to eliminate the influence of hyperventilation. The effect of the meal was observed for six to ten hours.

The basal respiratory quotients of normal and obese subjects were 0.825 and 0.767-an average of 13 and 21 determinations (subjects) respectively. A similar difference was observed by Hagedorn et al., although the values obtained by them were higher due to a diet which had been rich in carbohydrate. The ingestion of the fat meal brought the quotients of both groups to approximately the same levels-about 0.80 , indicating that both groups derived their extra energy for the specific dynamic action from the combustion of a similar mixture of carbohydrate and fat. This is opposed to the conclusions reached by Strouse and his coworkers from similar studies on a much smaller group.

Similar studies made on a group of 11 obese diabetic patients at a time when the diabetes was under control by diet (but one had been taking insulin), showed the average respiratory quotient to be 0.765 . The rise after the fat meal was less $(0.782)$ than in the non-diabetic obese group, suggesting that the available carbohydrate reserve is less in the diabetic.

The specific dynamic action was essentially the same for all groups, which opposes the idea that obese individuals are unique in this respect.

\section{Levels of Lactic Acid in Blood from Peripheral Vessels of Normal Subjects} and Subjects with Claudication. By GeORGE E. Brown and (by invitation) GRACE M. Roth, Rochester, Minn.

Levels of lactic acid, sugar, oxygen content and saturation of the blood of the femoral and brachial arteries and femoral and basilic veins have been studied in normal subjects and in subjects with occlusive disease of the major arteries of the upper and lower extremities. The relationship of levels of lactic acid and sugar has been investigated in relation to exercise and ischemic pains (claudication). The effect of cervicodorsal and lumbar sympathetic ganglionectomy on the lactic acid has been studied. A correlation has been demonstrated between the levels of lactic acid in the venous blood and the excessive fatigue and pain of intermittent claudication. The correlation is not sufficiently high, however, to indicate a causal relationship between the two.

Observations on the Circulation During and After Pregnancy. By C. Sidney Burwell, Nashville, Tenn., and (by invitation) W. David Strayhorn, JR., New York City, N. Y.

Normal young women in the early months of pregnancy were selected and trained as subjects. The acetylene method of Grollman was used to determine the cardiac output per minute; it was applied under the usual standard conditions in regard to rest and food. Observations were begun in the third or fourth month of pregnancy and continued at intervals of 2 to 6 weeks until delivery. They were repeated during the puerperium in each case.

In three of five women not only was there definite increase in cardiac output during pregnancy, but this was greater than the increase in oxygen consumption so that the arteriovenous difference was decreased.

In two patients there was no consistent elevation of cardiac output during pregnancy, although isolated observations showed values above normal. These patients had no unusual respiratory or circulatory symptoms or signs. 
In three women the cardiac output during the last weeks of pregnancy was lower than during several months preceding. In two of them it approached the values observed after delivery.

In all five women the cardiac output and the $\mathrm{A}-\mathrm{V}$ difference after delivery were not beyond the limits of normal.

No striking variations in blood pressure were observed. The pulse was more rapid during than after pregnancy.

Water and Sodium Chloride Balance in Patients Before and After Surgical Operations. By John D. Stewart and John H. Talbott (by invitation) and Edward D. Churchill, Boston, Mass.

The water and salt balances of 16 patients were studied in several types of surgical operations. In 3 patients on whom a herniotomy was done no significant negative balance of sodium chloride was observed. The largest decrease in serum chloride was 3.0 m.Eq.; the average weight loss in the 5-day period of observation was $2.5 \mathrm{kgm}$.

In 4 patients on whom a partial gastrectomy was performed the average negative balance of sodium chloride was 44 grams. The average decrease in serum chloride was $2.7 \mathrm{~m}$.Eq. and the greatest weight loss was $1.7 \mathrm{kgm}$. In calculating the salt balance account was taken of chloride in vomitus and urine only. In the absence of diarrhea a small amount was presumed to be excreted in the stools. The remainder of the amount not accounted for was assumed to be lost in the sweat and drainage from the wound.

In 2 patients, on whom three-stage thoracoplasties were done, interesting findings were the changes in serum chloride. Four days after the first stage operation there was a decrease of 12.4 and $18.7 \mathrm{~m}$. Eq. in the respective patients. Following the second stage operation the greatest fall was 6.6 and $8.0 \mathrm{~m} . \mathrm{Eq}$. and following the third stage was $1.4 \mathrm{~m}$.Eq. in the first patient. In the absence of noteworthy changes in the sodium chloride intake and output the above is taken as evidence of adjustment and adaptation to repeated loss of salt.

Transformation and Dissociation of Pneumococcus. By M. H. DAwson, New York City, N. Y.

Previous work on transformation of type-specific pneumococcus by in vitro procedures is briefly reviewed. Evidence is presented which suggests that $S$ forms of one specific type may be directly transformed into $S$ forms of other specific types without passing through the intermediate $R$ phase.

A new colony variant of pneumococcus is described. This new colony variant presents characteristics strikingly different from those of the previously described $\mathrm{R}$ and $\mathrm{S}$ forms. The morphology of the individual organisms constituting the new colony variant is also quite unique. Evidence is presented which suggests that the new phase of pneumococcus is an indirect and not a direct product of the parent form, from which it is derived. On the other hand reversion of the new phase to its parent form appears to be sudden and abrupt. The observations indicate that the evolution of the various phases may be cyclical in character.

Bacterial dissociation in other species will be briefly discussed and the place of the new phase of pneumococcus in the general phenomenon of bacterial dissociation indicated. The evidence suggests that it will be necessary to revise the currently accepted terminology for dissociate forms of pneumococcus in accord with the following: (1) $\mathrm{M}$ (mucoid)-formerly $\mathrm{S}$ (smooth); (2) $\mathrm{S}$ (smooth)-formerly $\mathrm{R}$ (rough); (3) R (rough) - not previously described. 
Studies on Effective Barium Chloride Dosage. By Arthur C. DE Graff and (by invitation) Jean A. Curran, New York City, N. Y.

In 1909 Rothberger and Winterberg's fundamental researches established the basis for the present clinical use of barium chloride. It was found that small amounts injected intravenously in dogs prevented ventricular standstill after combined nerve stimulation. Applying this finding to Adams-Stokes' syndrome, Cohn and Levine in 1925 prevented seizures of ventricular standstill with doses of 30 to $60 \mathrm{mgm}$. three times a day. On the other hand as much as 0.6 of a gram a day has been given without toxicity or benefit. Because of this confusion as to dosage both therapeutic and toxic, the present investigation was undertaken : first, to ascertain if a definite end-point of effective dosage could be determined; second, to determine the effective barium chloride dosage on dogs uninfluenced by any anesthetic, narcotic or operative preparation; and third, to compare dosage by vein and by mouth in both dog and man. Since in any drug in which the end-point of therapeutic effect is in doubt, it is desirable to increase the dosage to the point of mild toxicity, experiments were carried through to this level.

It was found that in dogs 0.41 to $0.91 \mathrm{mgm}$. injected intravenously per kilogram of body weight caused mild toxicity and unmistakable changes in the electrocardiogram, namely ventricular premature contractions, frequently with coupling, and changes in the character of the $T$ wave. When given by mouth 9.7 to $18.9 \mathrm{mgm}$. were needed to achieve similar results. Doses of over twice this amount caused moderately severe toxicity, but there were no fatalities. In man, 0.63 to $0.88 \mathrm{mgm}$. per kilogram of body weight were needed intravenously to give a definite end-point, while 3.7 to $13.2 \mathrm{mgm}$. per kilogram had to be administered by mouth to get parallel results. It was found that intravenously the greater the speed of injection the greater the effect. Electrocardiographic changes caused by barium chloride given by mouth generally persisted as long as 6 to 7 hours, but disappeared inside of 18 hours.

\section{Conclusions}

1. The electrocardiogram reveals changes following barium chloride which are constant and furnish an end-point as a definite guide in effective dosage. This is probably above the therapeutic dosage and though mildly toxic is far below the lethal dose.

2. The electrocardiogram furnishes a guide as to the rate of elimination.

3. Using these end-points, fairly constant relationship exists between the kilogram body weight and effective intravenous dosage.

4. For a given speed of injection there is a remarkably close comparison of effective dose by vein per kilogram of body weight between subjects, both dog and man.

5. Using electrocardiographic changes as our end-point of dosage we have shown the variability of comparative effective dosage by mouth from one subject to another.

\section{An Aid in the Diagnosis of Subacute Bacterial Endocarditis. By ClifFord}

L. Derick and Samuel A. Levine, Boston, Mass.

Derick and Fulton in their paper on skin reactions of patients and normal individuals to protein extracts of streptococci reviewed the literature concerning the response of patients with subacute bacterial endocarditis to skin injections of streptococci and their products.

Since that time we have continued these observations. In all, 20 patients 
with this disease have been studied. Thirteen of these showed a positive blood culture. The other 7 had all the clinical evidences necessary for this diagnosis.

Nucleoprotein extracts of hemolytic, green and indifferent streptococci were used as test materials. Only one case in which the diagnosis was not confirmed by blood culture showed a mildly positive response to the hemolytic streptococcus nucleoprotein. In all the other instances the tests were negative. In addition, one patient was tested with $0.2 \mathrm{cc}$. of a 24-hour broth culture of the autogenous viridans strain and another with approximately twenty million living organisms of Streptococcus scarlatinae. Both of these patients failed to show any reaction.

All cases where subacute bacterial endocarditis was suspected on admission were tested as a routine procedure. Since none of the patients proven to have subacute bacterial endocarditis showed a reaction, the finding of a positive test practically rules out this diagnosis. We have found this test of considerable diagnostic value.

The Effect of Arteriosclerosis and of Benign and Malignant Hypertension on the Area of Histamine Flares. By A. Carlton Ernstene and (by invitation) Maurice Snyder, Cleveland, Ohio.

In 30 normal individuals between the ages of 18 and 58 years, the average area of the flare produced by injection of histamine into the skin of the forearm was $31 \mathrm{sq}$. cm. The smallest flare observed had an area of $18 \mathrm{sq} . \mathrm{cm}$., while an area of less than $25 \mathrm{sq} . \mathrm{cm}$. was observed in only 6 individuals. In a group of elderly subjects with advanced grades of arteriosclerosis but with normal arterial blood pressure, flares of reduced area usually were recorded; while in other patients with slight or moderate thickening of the arterial walls, little or no diminution was the rule. Flares of normal area were obtained in 21 individuals with essential hypertension of the benign type. In 11 subjects with malignant hypertension, however, the average area of the flare was 14 sq. $\mathrm{cm}$. and in only one patient did it exceed $19 \mathrm{sq}$. cm. Only two of the patients presented an advanced grade of arteriosclerosis.

Lewis demonstrated that the flare following a histamine stimulus results from dilatation of the strong arterioles of the skin. The diminution in the area of the flares observed in subjects with malignant hypertension and in those with advanced arteriosclerosis suggests the presence of structural changes in the walls of these vessels, although in malignant hypertension the possibility of severe and permanent vasoconstriction must be considered.

The results of the investigation indicate that measurement of the size of the histamine flare affords data of considerable importance in the clinical study of patients with essential hypertension.

The Relationship of Cerebrospinal Fluid Pressure to Systemic Blood Pressure. By Frank Fremont-Smith and (by invitation) H. Houston Merritt, Boston, Mass.

A comparative study of systemic blood pressure and cerebrospinal fluid pressure has been made in over 1600 patients.

In 1418 patients the systolic blood pressures ranged from 50 to $300 \mathrm{~mm}$. $\mathrm{Hg}$ and the diastolic blood pressures ranged from 30 to $190 \mathrm{~mm}$. Hg. A study of these cases showed no significant correlation between the level of blood pressure and the cerebrospinal fluid pressure.

In 125 patients with elevated cerebrospinal fluid pressure, varying from 200 to over $1300 \mathrm{~mm}$. of water, the blood pressure was rarely elevated excepting when the cerebrospinal fluid pressure was extremely high, approaching the level of the normal diastolic blood pressure. In 22 cases with cerebrospinal 
fluid pressure varying from 500 to $800 \mathrm{~mm}$. of water, only 4 had a systolic blood pressure of $150 \mathrm{~mm}$. $\mathrm{Hg}$ or over.

In 63 patients with uremia or congestive heart failure, the cerebrospinal fluid pressure was frequently elevated but showed no correlation with the systemic blood pressure.

These results indicate that in man, as has been previously shown in animals, the cerebrospinal fluid pressure is not directly related to the systemic blood pressure and that an elevation of the cerebrospinal fluid pressure has no appreciable effect on the systemic blood pressure until the cerebrospinal fluid pressure level approaches the normal level of the diastolic blood pressure. When this occurs the systemic blood pressure becomes elevated to maintain cerebral circulation. A short discussion of the physiological mechanisms involved is given.

\section{Conclusions}

1. The level of systolic or diastolic blood pressure has no appreciable influence upon the cerebrospinal fluid pressure.

2. In uremia and congestive heart failure the cerebrospinal fluid pressure is frequently elevated.

3. The level of cerebrospinal fluid pressure has no appreciable effect on systemic blood pressure unless the cerebrospinal fluid pressure is greatly increased so as to approach the level of the diastolic blood pressure. Under these circumstances there is a rise in the systemic blood pressure.

The Interpretation of the Blood Sedimentation Rate (With Reference to Curves Obtained with Special Recording Apparatus). By A. ProskouriakofF (by invitation) and Burgess Gordon, Philadelphia, $\mathrm{Pa}$.

Comparisons are made between curves obtained with the usual technique of interval charting and those with a special electrical recorder which plots continuously the level of sedimentation. The data suggest that variations in the degree and rate at certain periods may be significant in the interpretation of the curves.

A Critical Examination of Methods for Determining the Cardiac Output in $\mathrm{Pa}$ tients with Cardiac Disease. By T. R. Harrison and (by invitation) Arthur Grollman, Ben Friedman, and Gurney Clark, Nashville, Tenn.

The accuracy and applicability of the acetylene method, the Burwell-Robinson method and the venous plateau method have been studied by comparing them with each other and by testing the validity of the assumptions underlying them. In normal subjects and in certain persons with mild congestive heart failure the two latter methods agree excellently with the acetylene method, which is based on an entirely different principle. However, the three methods, as ordinarily applied, disagree in certain patients with heart failure and these have been the object of special studies, from which the following conclusions are drawn:

1. In certain cases with heart failure, the Burwell-Robinson method may occasionally yield inaccurate results and therefore cannot be used with safety.

2. The venous plateau method gives accurate results when certain rigid criteria are adopted. For technical reasons and because of the discomfort to the subject involved in the procedure, it is not usually the method of choice.

3. The acetylene method may yield false results when only one determination of the arteriovenous difference is made at a single rebreathing. When two 
measurements are made of the arteriovenous difference during a single rebreathing and are found to agree, the results are accurate. Because of its technical advantages this acetylene plateau method is the procedure of choice.

Criteria have been described whereby in a given case the applicability of a given method may be tested, so as to have no doubt of a given result. Unless these criteria are rigidly adhered to, markedly erroneous results may be obtained. In patients with severe congestive heart failure these criteria may be impossible of fulfillment.

The Interference with the Pulmonary Capillary Circulation by Fat and the Effect of Intravenous Alcohol Dextrose. By Louis G. Herrmann (by invitation) and George R. HerrmanN, Galveston, Texas.

Rabbits and dogs were carefully selected and in double pairs injected at a uniform speed and without undue force at the rate of $1 \mathrm{cc}$. per minute with warm $\left(37^{\circ}\right.$ C. ) liquid, sterile, neutral fat in doses of $1 \mathrm{cc}$. per kilo of body weight. One animal of each series was kept as a control. Manifestations of disturbances of pulmonary circulation and the resulting anoxemia, as extreme restlessness, severe dyspnea and cyanosis, appeared rather promptly. The symptoms consistently disappeared almost immediately following the intravenous injection of $5 \mathrm{cc}$. per kilo of body weight of the alcohol-dextrose solution. This was repeated at the end of 12 hours in two of the series and in 24 hours in one of the remaining two. At the end of 48 hours all animals were sacrificed and the lungs promptly and completely fixed showed a sharp decrease in the amount of neutral fat globules in the pulmonary capillaries according to the number of injections with almost a complete clearing in those animals that had received three injections.

Data are being accumulated on the types and amounts of neutral fat, fatty acids, cholesterol and phosphatids by volumetric determination in the arterial and venous blood, in the general and in the pulmonary circulation, before and after the injection of neutral fat, and after the injections of alcohol-dextrose. The quantitative distribution and the rate of disappearance of fat from the blood stream have been determined.

Clinical Manifestations of Hypo- and Hyper-Magnesaemia. By ARTHUR D. Hirsch FELDER, Minneapolis, Minn.

Although blood magnesium is usually constant ( 2 to $3 \mathrm{mgm} . \mathrm{Mg}$ per $100 \mathrm{cc}$.) in normal individuals, we have observed two distinct clinical groups in which significant alterations of blood magnesium were associated with concomitant clinical manifestations.

1. Low blood magnesium ( 0.9 to $1.37 \mathrm{mgm}$.) was found in 10 cases, all manifesting twitching or convulsions. One of these was parathyroid tetany, two epilepsy, one cerebral injury, the others acute or chronic nephritis. Three of the latter were given Epsom salts by mouth, whereupon the blood magnesium rose to from 3.3 to $5.8 \mathrm{mgm}$. $\mathrm{Mg}$, and twitchings or convulsions disappeared.

There thus seems to be a definite clinical syndrome associated with low blood magnesium.

2. High blood magnesium: This was found especially in nephritics after the administration of Epsom salts. In normal individuals 20 to 30 grams $\mathrm{MgSO}_{4} .7 \mathrm{H}_{2} \mathrm{O}$ by mouth does not significantly raise the blood magnesium and about 40 per cent is excreted in the urine in 24 hours. In nephritics less of the ingested $\mathrm{Mg}$ is excreted in the urine, and the blood magnesium rises.

Twenty to 30 grams $\mathrm{MgSO}_{4} \cdot 7 \mathrm{H}_{2} \mathrm{O}$ administered to 9 patients with acute 
and chronic glomerulonephritis raised blood magnesium from near normal to 9.8 to $11.3 \mathrm{mgm}$. All these patients were definitely more drowsy when at these levels. Two nephritics with blood magnesium 8.9 to $9.0 \mathrm{mgm}$. without administration of $\mathrm{MgSO}_{4}$ were definitely drowsy and unresponsive.

Coma is induced in animals when the blood magnesium approaches $17 \mathrm{mgm}$. $\mathrm{Mg}$ per $100 \mathrm{cc}$.

Elevation of blood magnesium to about two-thirds of the coma level thus seems to be accompanied by a tendency to somnolence.

It is probable that repeated purgative doses of Epsom salts by mouth can induce coma in nephritics, and that many cases of supposed uremic coma are really magnesium coma induced by Epsom salts. From this coma animals and probably patients can be awakened and their lives prolonged by intravenous calcium chloride.

Nephritic rabbits whose blood magnesium is moderately elevated (5 to $10 \mathrm{mgm} . \mathrm{Mg}$ ) by orally administered $\mathrm{MgSO}_{4}$ are hypersensitive to morphine.

The Blood Pressure in Stenosis of the Isthmus. (Coarctation) of the Aorta. By JoHn T. King, Baltimore, Md.

The blood pressure in the arms in cases of isthmus stenosis (coarctation) of the aorta is so often greater than normal that many observers have assumed hypertension to be a necessary part of the diagnostic picture. In the author's experience, hypertension was found in the arms in ten of eleven cases. One patient showed typical signs of coarctation including relative hypotension in the legs, but in her case the arm pressures were always within normal limits.

An analysis of the literature showed normal arm pressures present in twenty per cent of cases of isthmus stenosis in which pressure readings were recorded. The author's case is the seventeenth reported instance of normal arm pressure in coarctation of the aorta.

The Effects of Alternate Suction and Pressure on Blood Flow in the Lower Extremities of Normal Subjects and of Patients with Peripheral Vascular Disease. By Eugene M. LANDIs and (by invitation) JoHN H. GibBON, JR., Philadelphia, Pa.

The lower extremities of normal subjects and of patients with peripheral vascular disease were inserted into an aluminium box through a well fitted, heavy rubber diaphragm. Negative pressure, amounting to $120 \mathrm{~mm}$. Hg, was applied for 25 seconds, alternating with positive pressure, amounting to $100 \mathrm{~mm}$. $\mathrm{Hg}$ for 5 seconds.

Increase in blood flow to the distal portion of the lower extremity was identified by thermo-electric measurements of digital skin temperatures. In normal subjects the extremity exposed to alternate suction and pressure cooled more slowly than the control extremity. When vasoconstrictor tone was diminished slightly by immersing one forearm in warm water the temperature of the extremity exposed to suction and pressure rose earlier, and to a greater height, than that of the control extremity. With the subject chilly and the extremities cold, suction and pressure in some observations had no measurable effect on blood flow until vasoconstrictor tone was slightly diminished by warming the body. In most instances the control extremity cooled while the rising temperature in the extremity exposed to suction and pressure indicated an increase in blood flow on that side.

In patients with peripheral vascular disease alternate suction and pressure was accompanied by conspicuous warming (and therefore by increased blood 
flow) in extremities showing no rise in temperature during anesthesia of the posterior tibial nerve. In the presence of obstructive lesions of more moderate grade the more involved (and cooler) extremity was made the warmer of the two extremities by alternate suction and pressure.

The results indicate that this apparatus may possibly be used as a "peripheral heart" to increase blood flow in the lower extremities of patients with peripheral vascular disease.

The Normal White Blood Cell Picture. By Edgar Jones and Doran J. Stephens (by invitation) and John S. LAWRENCE, Rochester, N. Y.

Data have been collected from observations on sixteen normal adults which indicate that there are slight variations in the number of the white blood cells in the peripheral circulation under basal conditions. These fluctuations have been found to be greater than our error of technique. Determinations of the number of white blood cells have been made at 15 minute intervals over four hour periods. Differential counts have shown that all of the cells show fluctuations but the greatest of these are shown by the neutrophils. No rhythm, no showers of "non-motile" cells and no appreciable variations in the number of "stab" forms have been found.

The effect of change of posture has been carefully investigated in thirty-five normal adults and eighteen adults with a variety of clinical disorders. No significant variation has been found to be associated with change in position.

Observations on the effect of digestion on the white blood cell count in thirteen normal adults have shown a slight increase in the number of the cells in the majority of these individuals two to four hours after the ingestion of a large meal. The neutrophils account for most of the changes in the total number of white blood cells in these subjects.

Observations of the Cerebral Blood Flow in Man. By F. A. GibBs and E. L. GibBs (by invitation) and W. G. Lennox, Boston, Mass.

A thermo-electric blood flow recorder has been devised for measuring the rate of blood flow through the internal jugular vein of man. Continuous records have been made over a period of three or four hours of the variations in flow through the internal jugular vein of unanesthetized human subjects. Records have been obtained of the flow associated with epileptic convulsions and with sleep. Observations so far fail to show significant changes in cerebral blood flow immediately preceding these events. The effect on cerebral blood flow of alterations in blood gases and of the administration of certain drugs has been studied. High $\mathrm{CO}_{2}$ and low $\mathrm{O}_{2}$ increase and low $\mathrm{CO}_{2}$ decreases cerebral blood flow. Adrenalin produces a marked increase in flow, as do also amyl nitrite and acetyl cholin unless the fall in systemic blood pressure is too great. Caffeine and ergotamine tartrate produces a more lasting increase in cerebral blood flow than any of the other agents studied.

Single Cell Inoculations with Treponema Pallidum. By Clarence S. Thomas (by invitation) and Hugh J. MoRgan, Nashville, Tenn.

The development of syphilis in the rabbit following intratesticular injection of test material affords positive evidence of the presence of Treponema pallidum in the inoculum. Failure to thus infect has been interpreted as indicating the absence of Treponema pallidum in the inoculum. Inasmuch as this interpretation is widely used in the study of experimental syphilis (immunity; chemotherapy) it seemed desirable to test the validity of the assumption upon which it is based. 
In preliminary experiments inocula, in which the presence of a few organisms seemed probable, failed to produce infection. An attempt was made to definitely determine this point by the inoculation of single organisms. A drop of diluted syphilitic testicular emulsion was placed in a moist chamber. By dark field illumination and with a micro-manipulator it was possible to aspirate one or several organisms into fine glass pipettes. The pipette tips were immediately placed in syringe needles and injected into the testicles of rabbits. The testicles were then vigorously massaged.

Eighteen rabbits were thus injected with single organisms (11 Nichols strain; 7 " S" strain). Four additional animals were inoculated, three with two organisms each (Nichols strain) and one with six organisms ("S" strain). All remained normal. At appropriate intervals transfers to a second series and from the second to a third series of rabbits were made, all with negative results. Immunity to the homologous strain was not present in those animals of the third series which were re-inoculated.

The Cholesterol Content of the Blood in Obesity Including Observations. of the Effect of a Diet Low in Fats, Carbohydrates and Total Calories on the Blood Cholesterol. ${ }^{1}$ By MAURICE BRUGER ${ }^{2}$ (introduced by Herman O. Mosenthal), New York City, N. Y.

Two hundred and seventy-seven plasma cholesterol determinations were made on seventy-five cases of obesity. The percentage of overweight varied from 20 to 122 per cent, with an average of 47.7 per cent for the group.

Uncomplicated (frank, exogenous) obesity is associated with a normal plasma cholesterol. Diabetes mellitus, hypertension, arteriosclerosis and hypothyroidism tend to elevate the plasma cholesterol in the obese.

The normal plasma cholesterol in obesity is not affected materially by lowcaloric, low-fat diets in patients followed at regular intervals for approximately one year. The hypercholesterolemia in obesity complicated by diabetes mellitus, etc., usually shows a distinct elevation the first few weeks on low-caloric, lowfat diets but tends to fall appreciably below the control level following several months on such a régime.

General considerations of diet and loss in weight in the obese in relation to the plasma cholesterol are discussed.

Leukocytosis Following the Intramuscular Injection of Liver Extract. By William P. MURPhy and (by invitation) JoHn H. Powers and KathaRine Humphreys, Boston, Mass., and Cooperstown, N. Y.

Determinations of the total white cells and the total number and percentage of polymorphonuclear neutrophiles in the peripheral circulating blood of 16 normal subjects before and after the intramuscular injection of liver extract have been presented in graphic form. The individuals were divided into 2 groups, ambulatory and recumbent.

The average maximal increase in the total number of white cells of the ambulatory group was 94.1 per cent higher than the average of all control counts and occurred 7 hours after the extract was administered. The greatest individual response in this group was 185 per cent and the lowest was 23 per cent above the average of the 4 control counts made on each of these 2 subjects the previous day. The average maximal increase in total white cells of the patients of the recumbent group was 72 per cent above the normal level and

${ }^{1}$ Aided by a grant from the Josiah Macy, Jr., Foundation.

2 Oliver Rea Fellow in Medicine. 
occurred 6 hours after the injection of liver extract. The highest and lowest individual responses in the members of this group were 101 and 20 per cent.

A similar increase in the total number of white cells and the total number and percentage of polymorphonuclear neutrophiles was obtained in one patient with influenza.

The leukocytosis in every instance was due to an increase in the polymorphonuclear neutrophiles.

The Occurrence of Pneumococcus Variants in Lobar Pneumonia. By JoHN R.

Paul and (by invitation) J. A. Lawrence, New Haven, Conn.

Whether or not $S$ pneumococci dissociate into avirulent variants during the clinical course of lobar pneumonia is the subject of this report. The work has been based upon recent observations upon the in vitro dissociation of $\mathrm{S}$ pneumococci which show that beside the well recognized and easily revertible, intermediate and $R$ variants, there are also so-called $R G$ variants, some of which are bile insoluble and apparently indistinguishable from Streptococcus viridans. These are difficult to revert back to the $\mathrm{S}$ forms.

Twenty-seven cases of lobar pneumonia were studied with daily throat cultures upon which differential bacterial colony counts were made. A shift in the throat flora was found at or about the time of crisis; $\mathrm{S}$ forms diminish, and suspected, unstable $R$ and $R \mathrm{G}$ forms appear in great numbers during the first few postcritical days. To establish the identity of these suspected $R \mathrm{G}$ forms the attempt to revert strains isolated before and after crisis was made in about twenty-five instances. Three successful reversion experiments are reported upon $\mathrm{R} G$ strains isolated in the first week after crisis. The results suggest that virulent pneumococci undergo marked dissociation within the human host during pneumonia. The clinical implications are briefly discussed.

Observations on the Living Choroid Plexus. By Tracy J. Putnam (Boston) and (by invitation) ERIC Ask-Upmark (Lund, Sweden).

It is possible to observe the living choroid plexus of the cat under the microscope. By micrometry, the arteries can be seen to contract and expand under nervous and chemical influences, much as do the pial vessels. If the surface is stained with methylene blue, the choroid ependyma, the muscular coat of the arteries and occasionally nerve fibers may be demonstrated. The axones of the subjacent white matter are easily stained. If fluoresceine be injected intravenously, it may be seen to escape through the walls of the capillaries and veins, particularly the latter. This is perhaps of significance in relation to the pathogenesis of some cerebral diseases in which the lesions have a perivascular distribution.

Tissue Metabolism in Secondary Anemia. By Herman H. Riecker, Ann Arbor, Mich.

The object of this experiment was to determine whether the tissues of animals made anemic by hemorrhage could utilize oxygen at the same rate as those of normal animals. Previous work by Anson and Mirsky, Keilen, and Warburg indicated the possibilities that the iron-containing respiratory pigment (hem) of the cell might be partially depleted by iron starvation.

A simple method was devised which seemed suitable for the study. Normal defibrinated rabbit's blood was oxygenated and 1 to 2 grams of the tissue macerated and mixed with the blood. Twenty cc. of the blood was used and the oxygen content determined before and after exposure to the tissue in a 
water bath for 1 hour; the difference in $\mathrm{O}_{2}$ content, minus that used by the blood alone, was taken as the amount consumed by the tissue. Liver and kidney tissues from 15 anemic and 15 control rabbits were used, the iron content of tissue and blood serum being determined.

Under these conditions tissues from anemic animals do not utilize as much oxyen as those of normal tissues by about 50 per cent. The results demonstrate the fact that, in general, anemia affects all the tissues and not the blood alone.

The Excretion of Bence-Jones Protein in the Nephrotic Syndrome. By Howard F. Root and (by invitation) Hazel M. Hunt, Boston, Mass.

A case is presented of a 12 year old boy showing edema, albuminuria, low serum protein content, inversion of the albumin-globulin ratio in blood serum and the hypercholesterolemia characteristic of nephrosis and excreting considerable amounts of albumin and of albumose of the Bence-Jones type. The 24hour excretion of albumin varied from a trace to 9.5 grams. The albumose varied in amount but it was possible once to isolate as much as 1.5 gram from a 24-hour specimen in a finely powdered condition by precipitation at $55^{\circ} \mathrm{C}$. This isolated material gave the characteristic tests for Bence-Jones protein. The use of a high protein diet (protein 130 to 160 grams, carbohydrate 160 grams, and fat 100 to 150 grams) and thyroid extract (gr. v daily) brought about the following results. In a period of 4 months anasarca disappeared; basal metabolism rose from -16 to +7 per cent; serum protein rose from 2.9 to 4.7 per cent. The albumin-globulin ratio returned to normal. The excretion of Bence-Jones protein in the urine ceased. The plasma cholesterol rose steadily from 439 to $1250 \mathrm{mgm}$. per $100 \mathrm{cc}$. A constant retention of nitrogen averaging 10 grams daily occurred during the first 6 weeks. Nitrogen balance was reached in 8 weeks. No cause other than the nephrotic syndrome was found for the occurrence of the Bence-Jones protein.

Even when the albumosuria was most marked no albumose was found in the blood plasma. This fact suggests that abnormality in the renal mechanism was responsible for the albumosuria rather than the formation of albumose in other tissues, transportation by the blood to the kidney and its excretion.

It has been held that the hypercholesterolemia of nephrosis is due to tissue starvation. The degree of tissue inanition in this case may be judged by the fact that for 6 weeks he retained nitrogen in amounts varying from 6 to 12 grams daily. The plasma cholesterol of $1250 \mathrm{mgm}$. is higher than any figure mentioned in Leiter's review of the subject. As yet the cholesterol has not begun to decrease although the clinical improvement is most marked.

The disappearance of edema when the serum protein remained at a low level indicates that some additional mechanism was involved in maintaining the osmotic pressure within the vessels. It is suggested that the high concentration of cholesterol acted in this manner to prevent edema.

Studies on Specificity of Streptococci. The Experimental Reproduction of Persistent Sneezing with a Streptococcus Isolated from a Case. By EDWard C. Rosenow, Rochester, Minn.

The streptococcus isolated from the nasopharynx of the patient on the eighth day of persistent sneezing, and from the brain and other tissues of inoculated animals, was grown in dextrose-brain broth and the cataphoretic velocity was determined in distilled water with the Northrop-Kunitz-Mudd apparatus.

Rabbits were inoculated intracerebrally, intratracheally and intraperitoneally, and dogs intracerebrally. Persistent sneezing, which continued to recur often 
for many hours, was produced by the different methods of injection of the live streptococcus as isolated and after many rapidly repeated subcultures in dextrosebrain broth, of suspensions of the heat-killed streptococcus and of filtrates of active cultures.

The lesions produced were typical of encephalitis and were mainly in the medulla.

The results in control animals injected in like manner with streptococci from patients having other diseases of the nervous system, were very different, in that sneezing was almost wholly absent and in that many animals revealed symptoms and other findings characteristic of the respective diseases studied.

The cataphoretic velocity of the streptococci as isolated at the time of the attack or shortly after in the case of persistent sneezing, and in the control group, before and after animal passage, was mainly neurotropic. The neurotropic velocity and concomitantly the property of producing sneezing, were lost promptly on ordinary aerobic cultivation.

A Significant Contrast Between Vasomotor Responses of the Peripheral Arteries. By W. J. Merle Scott and John J. Morton, Rochester, N. Y.

To determine the respective contributions of vasoconstriction and of mechanical occlusion has become essential in the clinical analysis of arterial diseases in the extremities. For this purpose two different vasomotor responses of the peripheral circulation have been used, viz. (1) the effect of vasoconstrictor paralysis and (2) that of vasodilator stimulation, the tacit assumption being made that the two resultant effects are approximately identical. In a group of fifteen individuals with normal blood vessels this is found usually to be the case, both paralysis of sympathetic vasoconstriction and stimulation of sympathetic vasodilatation causing an elevation of the surface temperature in the foot to the "normal vasodilatation level." Significant differences in the response of the local circulation to these two vasomotor reactions are found both in some individuals with normal and in those with pathological arteries. Occasionally the response to vasodilator stimulation is so much delayed or so much diminished as compared to the response to vasoconstrictor paralysis that the former is entirely unreliable for clinical purpose. As a corollary of this finding, in the clinical test unless an approximately maximal response to vasodilator stimulation is obtained the effect of vasoconstrictor paralysis should be ascertained.

On the Diagnosis of Myocardial Disease by Means of the Basal Cardiac Work. By IsaAc Starr, Jr., and (by invitation) J. S. Donal, L. H. Collins, JR., A. Margolies, and C. J. Gamble, Philadelphia, Pa.

The normal standards for basal cardiac work (cardiac output multiplied by mean blood pressure) have been determined by Starr, Collins and Wood (J. Clin. Invest., 1933, xii, 13). Since that investigation the basal cardiac work and the heart size have been determined for about 100 additional cases, including all the types of heart disease that could be secured. In this presentation it is proposed to discuss these results from the clinical point of view.

All cases in, or obviously threatened with, congestive failure were found to have myocardial insufficiency, i.e. their hearts were doing abnormally small amounts of work per unit of heart size. Therefore these estimations may appear to be of value in the diagnosis of this condition. A considerable number of cases of hyperthyroidism and hypertension showed the same abnormality.

On the other hand the majority of cases of angina pectoris and coronary 
occlusion (an old infarct was later demonstrated at autopsy in two patients) had a normal basal cardiac work.

Cases of effort syndrome show a small basal cardiac work, but give no evidence of myocardial insufficiency because they have small hearts and the work per unit of heart size is within normal limits.

Alterations in the Specific Gravity of the Plasma of the Blood with the Onset of Diuresis in Patients Suffering from Heart Failure of the Congestive Type. By Harold J. Stewart, New York City, N. Y.

The mechanism of the occurrence and elimination of edema in heart disease is still incompletely understood. Where, in a system regarded as circulating blood located between the tissues and the kidneys, must a stimulus be applied in order that diuresis may be initiated? Different types of diuretics may obviously act at different points. If the kidneys are first affected so that fluid passes from the circulating blood, concentration of the blood should occur. If, on the other hand, the process is initiated in the tissues, fluid first enters the circulating blood and dilution occurs and may be detected if it lasts long enough and is great enough.

Light on what the occurrences are when edema disappears may be gained by studying the blood to see whether concentration or dilution takes place. Changes in the specific gravity of the blood plasma may be utilized to trace the alterations in the blood. The method of Van Slyke and Moore has been used. It is now known that the specific gravity of the plasma of normal individuals varies from day to day within narrow limits only. It is moreover closely correlated with the amount of protein present in the blood. In cardiac patients, the occurrence of edema does not depend on the level of specific gravity of the plasma, which has in fact a normal value. We have investigated the curve of specific gravity with the onset and continuance of diuresis in patients suffering from heart failure of the congestive type, who exhibited edema and accumulations of fluid. One case will serve to illustrate the alterations which were observed: B. McL., female, white, 56 years of age, suffering from a second attack of heart failure of the congestive type, exhibited edema of the extremities. Arterial hypertension and enlargement of the heart were present. Rapid ventricular rate due to auricular fibrillation was present. Although the intake of fluids was restricted to $1200 \mathrm{cc}$. per day and she remained in bed, the output of urine did not rise beyond 200 to $300 \mathrm{cc}$. per day and she did not lose weight; the specific gravity of the plasma of the blood measured 1.0278. Digitalis 1.2 gram was given within 24 hours; the ventricular rate became slower, diuresis occurred, and the patient lost weight. The specific gravity of the plasma fell to 1.0240 and remained in that zone during diuresis, but when diuresis stopped the specific gravity returned to the level it had had beforehand (1.0280). Diuresis sometimes was accompanied by similar changes when it occurred spontaneously as a result of limitation in the administration of fluids and of rest in bed and also as a result of giving theocalcin. By taking samples of blood frequently, it was found that decrease in the specific gravity of plasma appeared to precede the onset of diuresis, and that it was possible to predict the occurrence of diuresis. Estimation of the total amount of protein excreted by way of the urine during the periods of diuresis failed to account for the low concentration of protein indicated by the alteration in specific gravity. The decrease was due, not to loss of protein from the blood, but to dilution of the blood by edema fluid. In another patient, in whom the specific gravity of the plasma of the blood before the onset of diuresis was 1.0270, the specific gravity of the edema fluid was 1.0084. With the occurrence of diuresis the specific 
gravity of the plasma fell to 1.0240 ; had approximately $400 \mathrm{cc}$. of edema fluid having a specific gravity of 1.0084 entered the blood, the amount would have been sufficient to reduce the specific gravity of the plasma to the observed level (1.0240).

Using alteration in specific gravity as a measure of concentration of protein in the blood, it appears that diuresis, in the presence of heart failure of the congestive type, depends on changes initiated in the tissues, and is accompanied by dilution of the circulating blood.

Constitutional, Hereditary and Familial Features of Pernicious Anemia. By Cyrus C. Sturgis and Raphael Isaacs and (by invitation) L. R. Gates, Ann Arbor, Mich.

A study of 680 consecutive patients with pernicious anemia and a similar number of non-pernicious anemia patients of the same locality and age groups was made, correlating the weight, hair color, eye color, ear length, blood pressure, spleen size, blood count, blood bilirubin, lymph node size, heart size, heart murmurs, gallbladder, age incidence, duration and individual symptoms. The disease incidence in the family and system incidence in the patients were correlated and the significance or non-significance was determined from Fisher's table of $\chi^{2}$. A similar study was made, correlating the various symptoms of the patients. Pernicious anemia occurred more frequently in the families of the pernicious anemia patients than in the others. No significant correlation was evident between the special system disease tendency in any individual patient and a history of similar system disease in the family, although there was a moderate tendency for the association of these symptoms in the presence of a family history of heart disease, gastro-intestinal, genito-urinary, and skin disease and tuberculosis.

The Absorption of Thyroxine from the Gastro-Intestinal Tract, with Special Reference to the Effect of Alkali. By Willard O. ThOMpson and (by invitation) Phebe K. Thompson, Samuel G. Taylor, III, and Lois F. N. DickIE, Chicago, Ill.

A large number of observations on twelve patients with myxedema show that pure synthetic thyroxine when given by mouth or directly into the duodenum has only a slight effect on the basal metabolism; whereas, when given by mouth in the form of its monosodium salt, it has about one-quarter to one-fifth as much effect as when given intravenously; and when given in solution with an excess of sodium hydroxide, it has a much greater effect which nearly equals its effect by the intravenous route. Dissolving thyroxine in an excess of sodium hydroxide results in the formation of the disodium salt. Squibb's thyroxine for oral use, which presumably contains a sodium salt of thyroxine and some thyroxine in peptide combination, has about two-thirds to three-fifths as much effect as thyroxine intravenously and about three times as much effect as the monosodium salt of synthetic thyroxine given orally.

Since pure thyroxine is insoluble in most solvents and its monosodium salt only slightly soluble, while the disodium salt and thyroxine in peptide combination are much more soluble, it would appear that the solubility of the thyroxine compound administered is an important factor in its absorption from the gastrointestinal tract and hence in its effect on the basal metabolism. The solubility of thyroxine peptide and polypeptide derived from desiccated thyroid during digestion in the gastro-intestinal tract may explain the fact that desiccated thyroid by mouth has about the same effect as thyroxine intravenously on the basis of equivalent iodine contents. 
The Dissolution of Clotted Plasma by Hemolytic Streptococci; the Relation of This Phenomenon to Acute Hemolytic Streptococcus Infections. By William S. Tillett and (by invitation) R. L. Garner, Baltimore, Md. Hemolytic streptococci isolated from patients are capable of rapidly liquefying clotted human plasma. Sterile Berkefeld filtrates of full grown broth cultures contain the fibrinolytic property to a high degree. Broth cultures and sterile filtrates of hemolytic streptococci (beta type) derived from human cases possess this property when tested with clotted human plasma. The human strains fail completely to liquefy the fibrin clot of plasma derived from many animals. Available strains of hemolytic streptococci derived from animals are incapable of liquefying human clot. Fibrinogen, chemically isolated from plasma, when coagulated with thrombin in the presence of suitable culture or filtrate, is rapidly liquefied. Dissolution under these conditions occurs with both animal and human material. The rate of liquefaction is such that $0.5 \mathrm{cc}$. of culture or filtrate transforms $1 \mathrm{cc}$. of solid, clotted plasma into a completely fluid state within fifteen to twenty minutes. A comparable amount of fibrinogen, when coagulated in the presence of culture, is completely liquefied in five minutes.

Pathogenic bacteria, such as pneumococci, green streptococci, typhoid bacilli, etc., similarly tested, have not exhibited a comparable fibrinolytic property.

The fibrin-digesting power of hemolytic streptococci suggests an explanation for the manifestations of acute streptococcus infections which are characterized by thin, fibrin-poor exudates such as are seen in the early stages of hemolytic streptococcus empyema.

By repeated tests on plasma obtained from patients ill with hemolytic streptococcus infections, recovery frequently parallels, or is followed by, the development in the blood of a property by which clot digestion is inhibited. Effective resistance to the activity of the fibrinolytic ferment is most commonly demonstrable in the plasma of patients recovered from suppurative hemolytic streptococcus infections. The development in the blood of recovered patients of the capacity to inhibit this bacterial activity seems to be a form of resistance which differs, in the parallel tests so far performed, from streptococcal agglutinins or the anti-streptolysin described by Todd.

Observations on the Etiological Relationship of Severe Alcoholism to Pellagra. By Tom D. Spies and H. F. DeWolf (introduced by Joseph T. Wearn), Cleveland, Ohio.

It is generally agreed that the pellagra found in the North is usually associated with severe alcoholism. This study demonstrates that over ninety per cent of the patients develop the lesions of pellagra following excessive drinking. Ten patients having typical "alcoholic pellagra" recovered from their disease while receiving an adequate diet and large quantities of corn whiskey. On theoretical grounds it may be considered that the whiskey predisposes to the development of pellagra either by destroying the so-called "pellagra-preventive" factor or by altering the gastro-intestinal tract so that it becomes incapable of assimilating the preventive substance. Likewise it has been suggested on theoretical grounds that foreign substances in the whiskey such as the higher alcohols, produce the lesions of pellagra.

It appears unlikely, however, that there is any specific deleterious material present in the many kinds of beverages taken. The present observations show that the consumption of large quantities of whiskey at the same time that an adequate diet is received does not interfere with the clinical improvement of 
the patients. This is strong evidence that alcohol does not directly inactivate either all of the gastric secretion or all of the potent substances in the food. It is well known that many individuals drink large quantities of alcoholic beverages for years without suffering from loss of appetite, vomiting or pellagra. Correlation of these findings suggests the following hypothesis: Severe alcoholic imbibition by some individuals causes inadequate ingestion of food by decreasing the appetite and often precipitates nausea and vomiting. These predispose to the development of pellagra because the person no longer receives an adequate diet but utilizes the calories in the alcohol.

The Clinical Significance of the Hyperactive Carotid Sinus Reflex. By Soma WeIsS and (by invitation) JAMES P. BAKER, Boston, Mass.

A study has been made of the circulatory and nervous system of 12 subjects who complained of dizziness and fainting, and in whom the mechanical stimulation of one or each of the carotid sinuses induced characteristic aura, dizziness, fainting and convulsive seizures. Three main types of cardiovascular responses were observed following stimulation of the sinus: (a) marked asystole or sudden slowing of the heart rate with or without marked fall in the arterial blood pressure; (b) marked fall in the arterial blood pressure, but without essential cardiac slowing; $(c)$ changes in the cerebral circulation without essential slowing of the heart rate, and without fall in the arterial blood pressure. Stimulation of the hyperactive carotid sinus reflex induced striking changes in the intracardiac conductive system: partial and complete heart block, temporary asystole of the ventricle with continued auricular contraction, nodal rhythm, ventricular extrasystoles, change in the shape of the $T$ waves, and complete inversion of the electrical axis in the heart. The observations also demonstrate that AdamsStokes syndrome can be induced reflexly.

Evidence is presented that the clinical symptoms and signs observed, as well as the cardiovascular changes, are due to stimulation of the sinus and not to direct motor vagal stimulation.

During stimulation of the reflex, the volume and velocity of blood flow became decreased. There was also a slowing of the blood flow through the brain. In the precipitation of fainting and convulsions the rate (time element), rather than the absolute deviation from the normal circulatory state of the brain, plays the primary ròle. This temporary, sudden ischemia, even if of short duration, sets up a sequence of events in the brain which proceeds independently to convulsions even if hyperemia promptly follows the ischemia.

Section of the carotid sinus nerve in two cases abolished the spontaneous fainting attacks.

Studies on the Prevention of Cholesterol Atherosclerosis in Rabbits. By KENNEth B. Turner and George B. Khayat (introduced by Randolph West), New York City, N. Y.

Atherosclerosis of the aorta was readily produced in rabbits by feeding cholesterol. The lesions were prevented in 17 of 19 animals by the simultaneous administration of dried whole thyroid gland with the cholesterol, while comparable thyroxin dosage was effective in only 3 of 10 rabbits. The changes produced by cholesterol were also prevented by potassium iodide in 17 of 18 animals. The bromide and chloride of potassium were ineffective. If complete thyroidectomies were performed upon the rabbits, potassium iodide no longer succeeded in preventing the intimal changes in the aorta. A close parallelism was observed between the level of the blood cholesterol and the presence or absence of arterial lesions. 
The Mitral Diastolic Murmur in Children without Mitral Valve Deformity but with Severe Rheumatic Carditis and Dilatation of the Left Ventricle. By Paul D. White and (by invitation) Edward F. Bland and T. Duckett Jones, Boston, Mass.

The Electrocardiogram in the Earlier Stages of Experimental Myocardial Infarction. By Frank N. Wilson, Paul S. Barker and (by invitation) Franklin D. Johnston, Ian G. W. Hill, and Gerald C. Grout, Ann Arbor, Mich.

A series of experiments was carried out in dogs in which various branches of the coronary arteries were ligated. Electrocardiographic studies were made either immediately after the ligation, or at some later period within the first twenty-four hours. In addition to the standard electrocardiographic leads and serial precordial leads, direct and semi-direct leads from the exposed heart were employed.

Immediately after ligation direct leads from the region supplied by the tied vessel yielded nearly monophasic responses, similar in all respects to those obtained from a region of the ventricular surface recently injured by burning or by other means. The RS-T deviation shown by these monophasic curves rapidly diminishes, but does not entirely disappear until the infarcted muscle dies some twelve or fifteen hours after ligation. The curious $T$ wave changes that occur in the coronary occlusion in man are also seen in direct leads from the margin of the infarcted area some hours after ligation. They are apparently due to alterations in the recovery process in this region.

Hypertension with Arteriolar and Glomerular Changes, in the Albino Rat Following Subtotal Nephrectomy. By J. EDWIN Wood, JR., and (by invitation) Clayton Ethridge, University, Va.

Hypertension and renal insufficiency following partial nephrectomy in rats have been reported by Chanutin and Ferris. It is the primary purpose of this study to describe the histological changes in the rat kidney subjected to functional strain by subtotal nephrectomy and to investigate a possible relationship between these changes and hypertension.

One hundred and eighty rats have been fed on a balanced diet. One hundred and fifty-three of these have had 80 per cent of the kidney tissue removed, and 27 control animals, simple laparotomy but no nephrectomy. Direct carotid blood pressure readings have been made and autopsy performed at intervals varying from 1 to 267 days. Of 153 animals with subtotal nephrectomy 68 have had blood pressures ranging from 70 to $139 \mathrm{~mm}$. $\mathrm{Hg} ; 42$ from 140 to 169 $\mathrm{mm}$. $\mathrm{Hg}$; 32 from 170 to $199 \mathrm{~mm}$. $\mathrm{Hg}$; and 11 from 200 to $230 \mathrm{~mm}$. Hg. The higher blood pressure levels have been found in rats with subtotal nephrectomy of 60 days' duration or longer and in each instance of hypertension degenerative glomerular changes have been present. The blood pressure in 27 control rats varied between 100 and $140 \mathrm{~mm} . \mathrm{Hg}$ with an average of $120 \mathrm{~mm} . \mathrm{Hg}$, a figure already fully established by Chanutin and Ferris.

During the early days of the experiment the tubules show rapid dilatation and epithelial hyperplasia with marked diffuse fatty change. This tubular fatty change is transient but reappears in localized areas at a later stage. Early, the glomeruli are distended and enlarged but free of degeneration.

Definite glomerular involvement begins to appear at approximately 40 to 70 days after operation as shown by marked epithelial cell enlargement with subsequent vacuolar degeneration and glomerular adhesions to the capsule. In 
the older animals there is further glomerular degeneration with a gradual loss of structural detail and progression to varying degrees of hyalinization and fibrosis. Glomerular fatty degeneration is striking and begins to appear in 80 to 120 days. This is also progressive and is marked after 170 days. Fatty degeneration of the afferent arterioles has been found at still later stages. These time intervals may vary. None of the pathologic changes has been seen in the control animals.

Summary: Hypertension frequently follows subtotal nephrectomy in rats. Fatty degeneration in the glomeruli and afferent arterioles, glomerular atrophy and hyalinization and tubular dilatation following subtotal nephrectomy have been observed and may be interpreted as a natural sequence of hypertrophy and degeneration brought about by functional strain.

The Response with Respect to Serum Volume and Composition after the Ingestion of Glucose in Diabetic Patients. By F. William Sunderman and (by invitation) Ennion Williams, Philadelphia, $\mathrm{Pa}$.

Blood was removed from diabetic patients, fasting, and one and one-half hours after the ingestion of glucose. The increase in the glucose concentration in the serum per kilogram of water was found to be accompanied by a decrease in the chloride concentration in approximately the ratio of $3.8 \mathrm{mM}$. to 1 . If the assumption be made that the solids of the serum, excepting glucose and chloride, are constant and on this basis the amounts of glucose, water, and chloride per unit of the remaining solids are calculated before and after the administration of glucose, it is found that the increase in the glucose is accompanied by an increase in both water and chloride. The solution transferred to the serum with the glucose is a hypotonic saline solution of an average chloride concentration of $60 \mathrm{mM}$. per kilogram of water, but with the addition of the glucose, it has on the average a higher osmolar concentration than the serum. The final result, therefore, is an increase in the glucose concentration in the serum, a decrease in the chloride concentration, an increase in the total osmotic pressure, and an increase in the serum volume. This would indicate that in the serum of the diabetic patient the disturbance resulting from the uptake of glucose is distributed among at least three other variables:-serum volume, osmotic pressure and chloride concentration. 